\title{
Agent-based Individual Network Teaching System for Modern History Outline of China
}

\author{
https://doi.org/10.3991/ijet.v13i04.8257 \\ Xianguo Jia \\ Bengbu Medical College, Bengbu, China \\ jiaxianguo110@163.com
}

\begin{abstract}
Individualize distance teaching introduces individual services in traditional network teaching by considering the learning conditions of students at different levels and the relevance of the content to individualize learning programs for students. Simultaneously, it provides students with the most matched teaching resources. At present, the common network teaching system has the problems of insufficient intelligence and lack of individuation. An agent-based individual network teaching system is an autonomous intelligence system with immediate feedback. It is provided with real-time monitoring and information filtering functions as well as teaching analysis and collaborative learning functions. Based on this study on Agent technology and the current situation of network teaching, an Agent-based individual network teaching system was constructed. The practical application effect of the network teaching system was analyzed using the Modern History Outline of China course as the object of experiment. This paper provides theoretical and data-driven support for the research on individualized distance teaching and network teaching system to examine potential development directions for future network teaching.
\end{abstract}

Keywords-Agent, network teaching system, Modern History outline of China, distance teaching

\section{Introduction}

With the development of network technology, network teaching systems including an individualized distance teaching mode have gained rapid development. Simply speaking, network teaching refers to a modern teaching method with the help of a computer network. It is mainly used for distance teaching [1]. Network teaching mainly includes two modes. The first is open network teaching (i.e. sharing network resources). Students choose and learn independently. The other is online interactive teaching based on a network communication platform [2].

In recent years, individualized distance teaching has become the mainstream of the network teaching mode. The common individual distance teaching system can achieve interaction between students and the system. Students can autonomously choose learning content according to their interests. The system may generate recommended teaching strategies according to the students' feedback. Current network 
teaching technology is mainly applied in networked course teaching. The link between network teaching systems and expert pages and academic forums has been realized. The sound network teaching system is being constructed step by step to enable it to be applied for teaching more subjects. In the common individualized distance teaching system, Web-based distance teaching systems have insufficient intelligence and poor guidance. The introduction of Agent technology can effectively solve the problems of insufficient teaching resources and a single teaching mode and create individualized and digital distance teaching services. Students can more conveniently gain access to teaching resources they need.

Based on analysis of domestic and overseas research about Agent technology and network teaching systems, a networked and expandable integrated teaching system was constructed using Agent technology theory, and empirical research was carried out by using the Modern History Outline of China course as an example. This research addresses the defects of network teaching systems in the aspects of intelligence and individualization, enhance teaching effectiveness and the quality of distance education, and provide support for further promotion of network teaching systems.

\section{State of art}

Since network technology is continuously developing and the popularity of network facilities is gradually improving, network teaching is attracting people's attention. The characteristics of network teaching such as convenience, strong interactivity and large resource capacity make it a research hotspot at home and abroad. Alvaro et al. [3] proposed a program of continuing medical education. Network science was proposed as a method to better comprehend the contribution of networking and interactivity among health professionals in professional communities regarding their learning and application of new practices over time. Feldstein et al. [4] reviewed interactions of 311 students reflected in the comments in a digital social learning community and adopted social network analysis to discuss the possibility of applying these interactions to evaluate students' critical thinking, communication, and collaborative feedback skills. The authors summed up the implications and recommendations for instructors who hope to apply Web 2.0 platforms and data to strengthen their understanding of students and class digital interactions and adopt the information to enhance courses. In another study, a research team chose colleges in China to study the design and application of a network teaching platform. Then they proposed corresponding strategies for enhancing research and development, improving application consciousness, and perfecting management to examine the function of a college network teaching platform in promoting teaching efficiency [5]. The research of domestic and overseas scholars shows that the network teaching system that is generally adopted at present lacks sufficient intelligence and individualization. The current system's usability is not strong and the interest appeal is low, so it is hard for students to combine network teaching with daily learning [6]. Additionally, current network teaching mostly shifts traditional teaching to a network without highlighting the features of network teaching such as strong interactivity, timely feedback and diversified 
teaching strategies [7]. Thus, more researchers are transforming the research emphasis to Agent-based individualized network teaching systems with stronger feasibility.

Intelligent Agent has been a hotspot recently. Since this technology has a prominent advantage in problem solving, it may become a new way for network teaching and will soon become an active research direction. For example, Agent technology is applied to design a distance intelligent teaching system that can conduct individualized learning designs for students. The analysis shows that Agent-based distance intelligent teaching systems are greatly different from previous network teaching systems. Students can gain an intelligent and individualized learning environment with strong interactivity through the system. This is critical for teaching efficiency and teaching quality improvement [8]. Some researchers propose that intelligent Agent systems can efficiently complete concept classification, problem description, problem solving and resource connection demands as well as provide a feasible way for individual recommendation of teaching resources and individual resource seeking [9].

Generally speaking, in most network teaching, one teacher synchronously teaches dozens or hundreds of students online. The biggest shortcoming of this technology is that the teaching process is teacher-centered and the same teaching scheme is applied for all students. Targeted instruction cannot be conducted for different students. Conversely, a private teacher may be employed for one-to-one teaching for students, but the defect of this method is that the cost is too large and rational allocation and utilization cannot be gained. Besides, due to geographical conditions and other conditional limits, most students cannot get the special tutorship of excellent teachers [10]. Agent-based individual network teaching systems will be the trend of network teaching development and have great significance for promoting system usability and meeting students' individual demands. However, Agent-based individual network teaching systems are not mature and need to be further improved. On this basis, an Agent-based individual network teaching system was constructed, and a relevant test is described in this paper.

The innovation advantages of the Agent-based individual network teaching system presented in this paper are as follows. First, the teachers in the network teaching system could provide corresponding learning strategies and learning resources for different students. For example, the teacher could be oriented to more students while ensuring the teaching quality. Meanwhile, students could put forward questions according to their degree of understanding. Second, the Agent-based individual network teaching system could achieve a rational allocation of teachers and teaching resources and realize sharing of the professional teachers' resources. 


\section{Theoretical construction}

\subsection{Definition of Agent}

Agent technology is a packed and designed computer system. It can achieve flexible and autonomous activity under a specific environment. Agent technology has the following characteristics [11].

First, an Agent owns autonomy and can achieve management of its behavior and state without the need of external intervention. Second, an Agent can exchange information with other Agents through its communication language to achieve cooperation, which is the sociality of an Agent. Third, an Agent can discover environmental changes in time and make responses. Finally, an Agent can actively execute a series of actions. Besides, the designed Agent possesses other features such as learning ability, adaptive ability and target selection. Because of these advantages, Agent technology can be widely applied in multiple subjects and fields [11].

\subsection{Structure of Agent}

Cloud computing depends on the numerous personal and enterprise computer terminals connected with internet. Therefore, according to such connection modes, cloud computing has the features of networking and integration and its theoretical basis is mainly divided into two parts: software-as-a-service and Web MVC framework technology.

An Agent is composed of different modules, and the information interaction mode and behavior and state control modes are different among various modules. They form an organic whole. According to the structure, an Agent can be classified into three structures:

The first is a thinking-type Agent. It owns basic logical reasoning ability and can properly think about the environment and behavior. Such an Agent can simulate or show awareness of the system users to achieve intelligent processing of individual behavior. A thinking-type Agent has high intelligence and optimizes individual and environment treatments.

The second is a response-type Agent. It displays intelligence by perceptions and actions. Such an Agent gradually evolves through collecting perceptions and actions and improves the whole system's functioning through continuous environmental interactions. Compared with a thinking-type Agent, a response-type Agent has higher execution efficiency and can be integrated in the environment sooner.

The third is mixed-type Agent that is developed on the basis of the above two types. It is a more rational mode of Agent construction. It has high flexibility and efficiency. The mixed-type Agent is composed of a thinking sub-system and a response sub-system. The thinking sub-system is responsible for reasoning, while the response sub-system is used to process the events without reasoning. 


\subsection{Design of Agent-based network teaching system model}

Network teaching includes teachers teaching, students listening and data processing. The teacher is responsible for teaching and tutoring, while students learn and consolidate. Both parties achieve transmission of teaching resources through the assistive technology and then complete the whole process of network teaching. The general framework of an Agent-based network teaching system model is shown as Fig. 1:

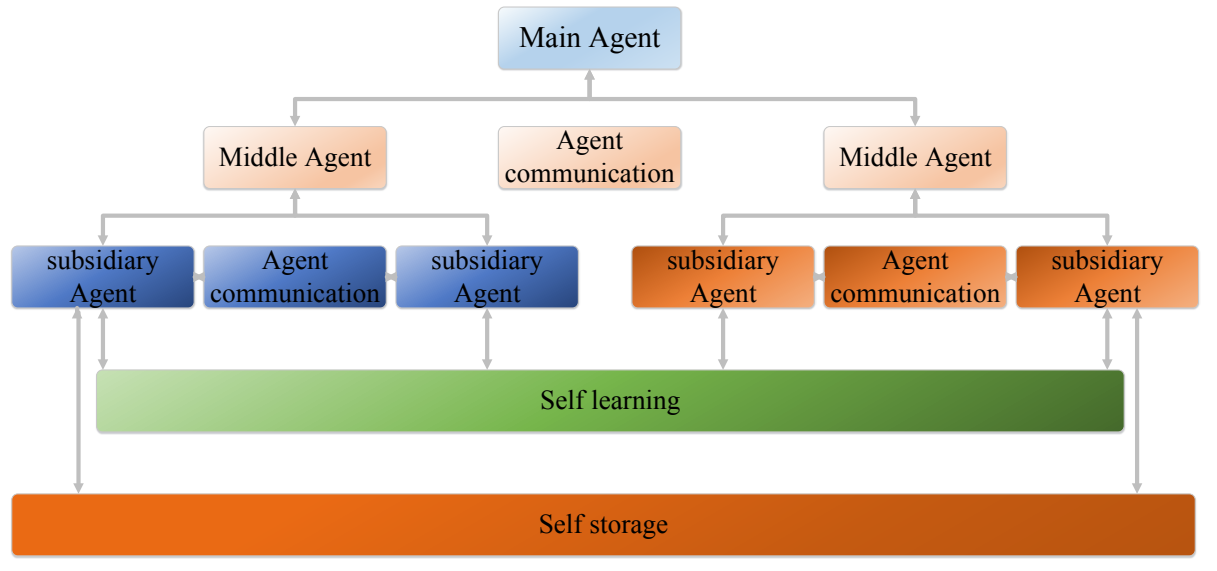

Fig. 1. General framework of Agent-based network teaching system model

It is known from the figure that an Agent-based network teaching system model includes three models: a teaching model, a teaching data model, and a listening model. To be specific, the system consists of an expression layer, logic layer and data layer. XML and JSP were used to develop the system and establish B/S application software system. XML is a meta-markup language, and JSP can be used to generate XML page. The detailed design of an Agent-based network teaching system is as follows:

Teaching model. A teaching model is the core of an Agent-based network teaching system responsible for all teaching activities, including information publishing, learning exchange, teaching tutoring, and testing. The teaching model includes two modules: teaching preparation and teaching, which are expanded by different types of Agents.

The teaching preparation module is responsible for developing the teaching strategy, organizing teaching content and confirming the teaching links. It completes teaching preparation in the early period and adjustment in the later period. This module is completed through a strategy-making Agent and a teaching content organizing Agent. The strategy making Agent can finish diagnosis and strategy making functions. Before teaching, the system can make proper teaching schemes for students based on their features. In the teaching process, the system can change teaching strategies according to students' learning progress. The strategy making Agent can make adjustments according to dynamic environmental changes. It is applicable to virtual class 
teaching. The major task of the teaching content organizing Agent is to refer to students' individual features and combine the teaching objective to form teaching content [6]. Agents can carry out intelligent analysis of the students' learning progress and recommend the next teaching resource for students in accordance with their mastery of the existing resources. XML grammar is used for the detailed design of the strategy making Agent as follows:

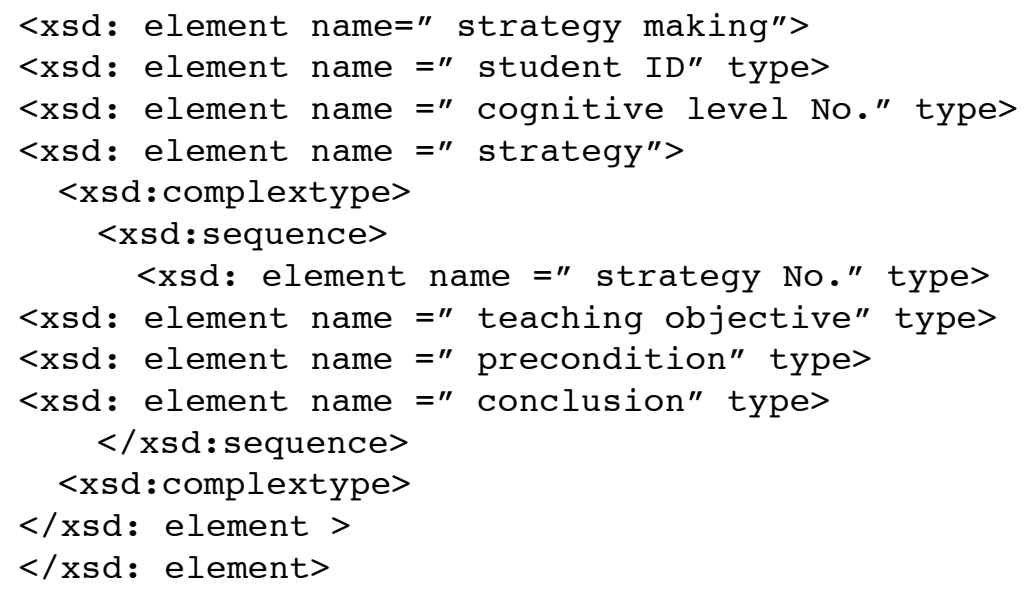

Based on teaching preparation, the teaching module is responsible for making the whole process of network teaching proceed smoothly, including tutoring, questioning/ answering and testing. The Agent-based network teaching system completes the detailed teaching process through the integration of multiple Agents, including a retrieval Agent, an exchange Agent, a question answering Agent, and a testing Agent. The structure is shown as Fig. 2:
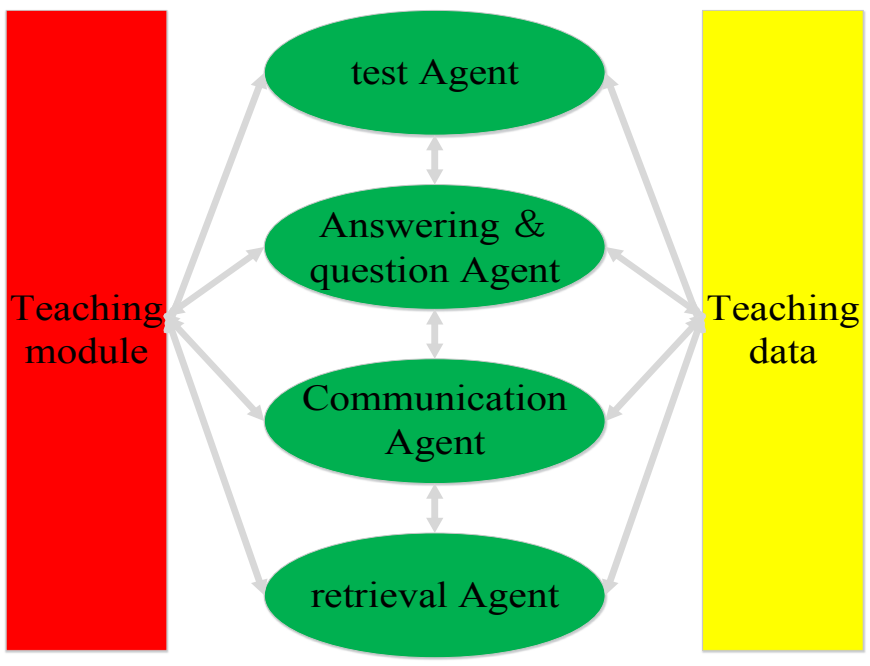

Fig. 2. Structure diagram of teaching module 
The retrieval Agent has index and seeking functions and can provide students with a directional search of teaching resources. The exchange Agent takes charge of processing the exchange information received and sent, including one-to-one transmission and one-to-more transmission. The question answering Agent can automatically provide answers to the questions proposed by students. Students' questions are not directly sent to the teacher but will first be matched in the common question library. When a satisfying response cannot be gained from the question library, it will contact the teacher. The testing Agent is in charge of testing students. According to a user's request, it combines individual learning progress to extract questions from the question library to form the test. Meanwhile, it feeds students' answers back to the system as a part of the teaching data.

Teaching data model. The teaching data module is mainly responsible for managing teaching videos and audio data transmitting, sending and replaying. It possesses the functions of receiving the users' instructions, returning information to the users and exchanging information. The teaching data model mainly includes three types: an instruction transformation Agent, an information display Agent and an information management Agent.

Listening model. First, the listening model contains basic information about the learning situation of each student, i.e. the data about students' learning progress. Second, it should be able to express the learners' cognitive state and accurately reflect comprehension of a specific student for concepts and content. Third, the listening model uses information about the students' preferences, including learning ability and other dynamic features. In addition, the listening model records the students' learning process and learning features in detail. According to the students' learning progress, cognitive level and interests, the listening model includes Fig. 3:

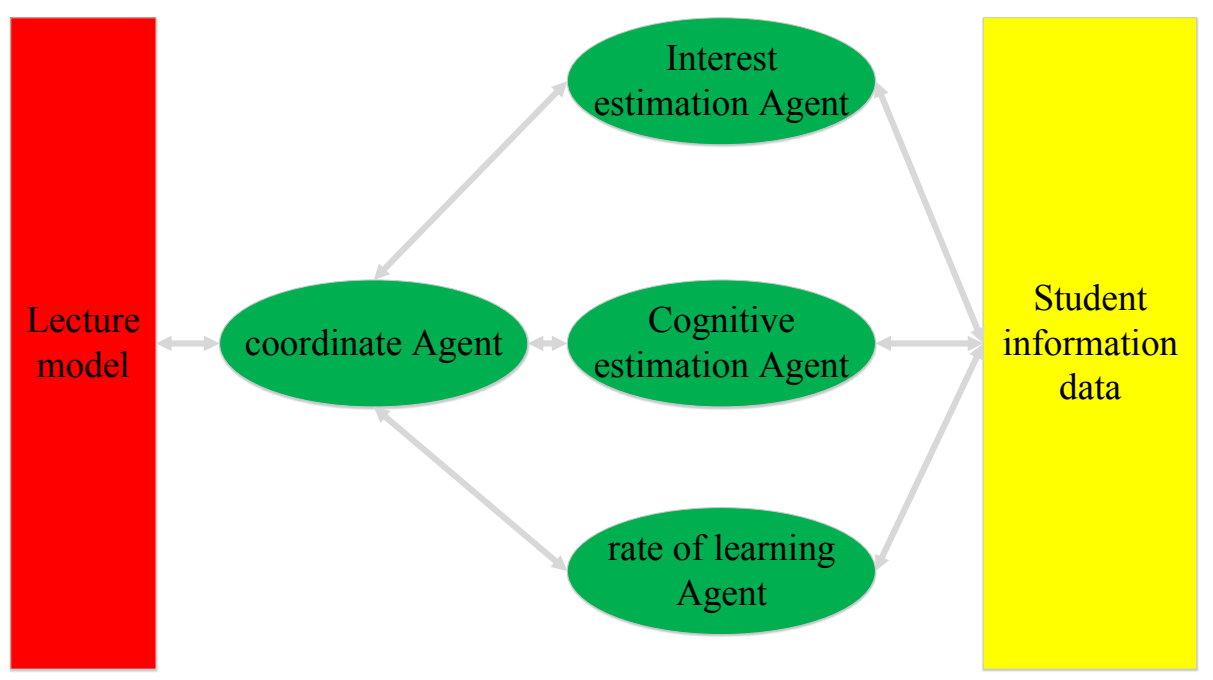

Fig. 3. Structure diagram of listening model 
Coordinating the Agent can achieve interaction between students and the system. When students use the system, the coordinating Agent is responsible for management of the other three Agents. The learning progress Agent is mainly used to record whether students have learned the course and mastered some knowledge points. The system can present the learning plan for users according to the records. The cognition estimating Agent classifies students through grading their cognitive level. The interest estimating Agent completes evaluation of the learning preferences through the students' basic information and their preference in learning process.

\section{$4 \quad$ Agent-based individual network teaching system construction for Modern History outline of China}

Modern History Outline of China is a professional and basic required course for history majors. It is also an elementary course in the university. Modern History Outline of China is an important part of Chinese history. Since different students understand Chinese history differently, a network teaching method is suitable for this course. Based on the theory construction of Agent-based technology, an Agent-based individual network teaching system was further constructed. Empirical research of the system was carried out using the Modern History outline of China.

\subsection{System construction}

The Agent-based individual network teaching system included the teaching model, teaching data model and multiple listening models that are inter-connected by a network. The structure diagram of the system is in Fig. 4.

As shown in the figure, the teaching process of the Agent-based individual network teaching system is as follows. First, the teaching model collects the teaching video and audio signals, receives the course materials stored in the teaching data model and transmits them to the listening model through a network. Second, students conduct distance learning through the listening model and send the questions to the teaching data model through the listening model. The teaching data model can transform students' questions to standard questioning code, seek the optimal answer through inquiring in the central processing unit and transmit the optimal answer to the students. If there is no corresponding answer in the teaching data model, the question will be sent to the teaching model and the teacher will answer it online. The questions and answers are stored in teaching data model. A teaching scene is shown in Fig. 5. 
Paper-Agent-based Individual Network Teaching System for Modern History outline of China

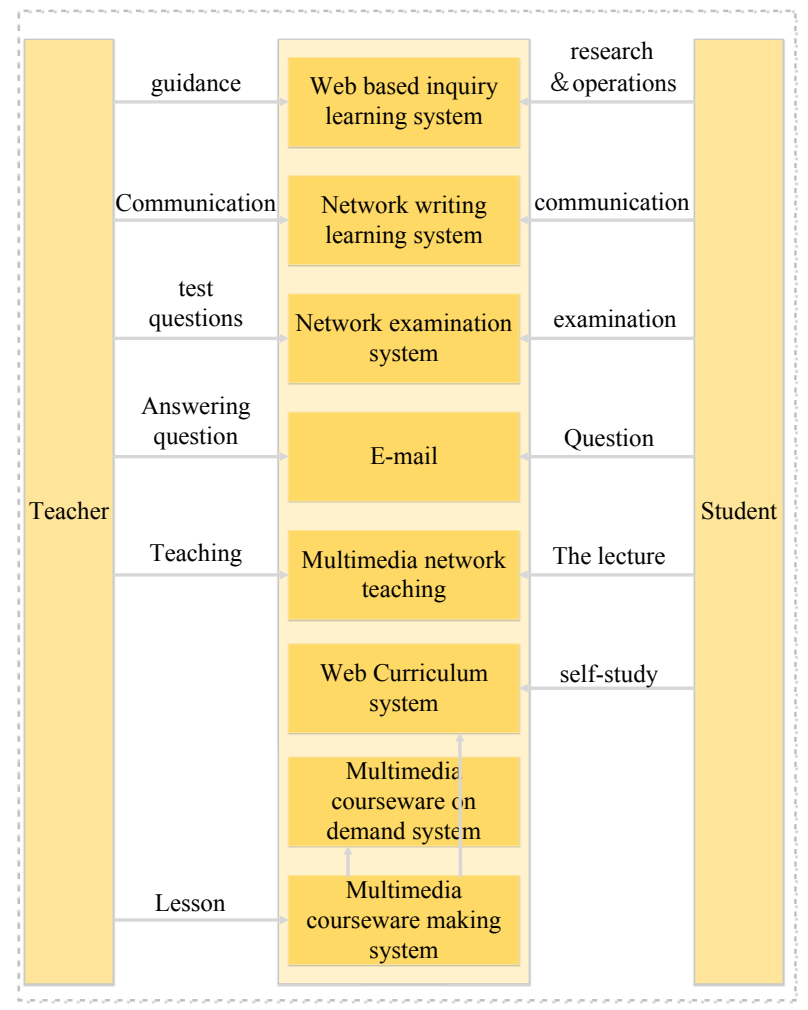

Fig. 4. Structure diagram of the system

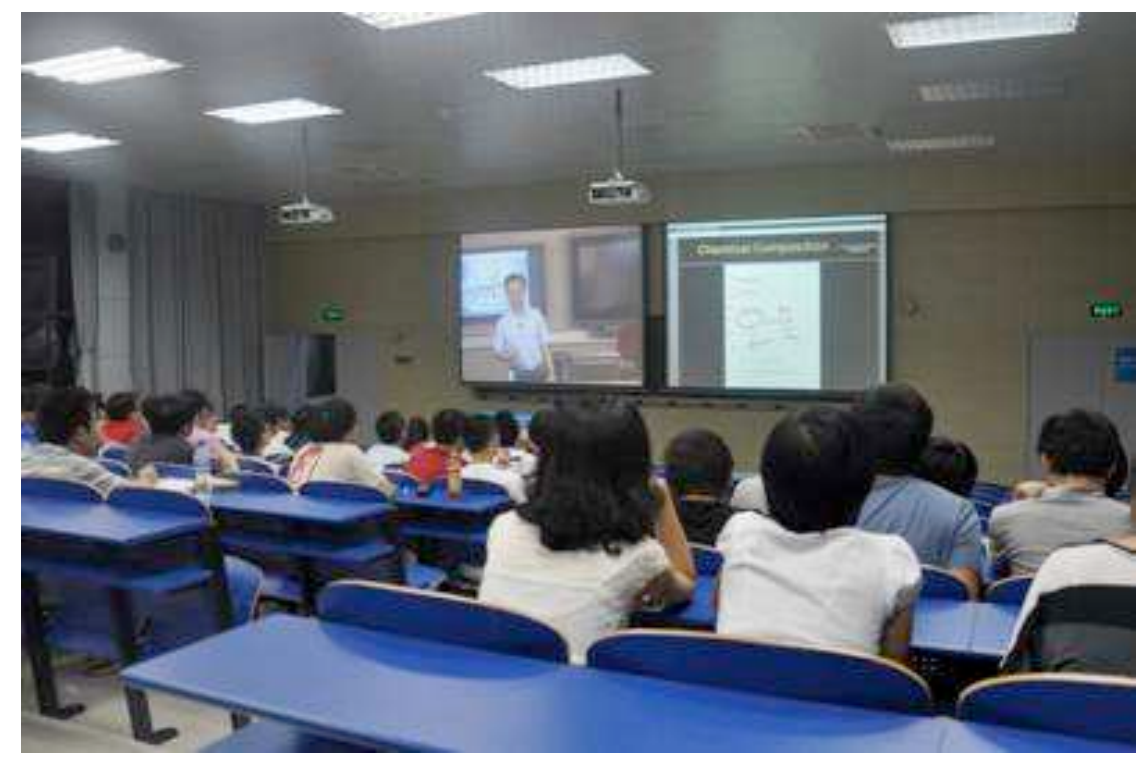

Fig. 5. Classroom view 


\subsection{Detailed implementation}

The key to the operation of an Agent-based individual network teaching system lies in the teaching data model. The detailed implementation process of the system is as follows:

First, the system adopts two English letters to code different teaching courses. In this paper, AA is used as the course code of the Modern History Outline of China.

Second, the teaching data model takes a 12-bit question code as the standard questioning code of the course, as shown in Table 1.

Table 1. Question code and question content

\begin{tabular}{|l|l|}
\hline \multicolumn{1}{|c|}{ Question code } & \multicolumn{1}{c|}{ Question content } \\
\hline AA0203000018 & How many research fields does Modern History outline of China include? \\
\hline AA0203000029 & $\begin{array}{l}\text { Which similarities and differences exist among Modern History outline of China, } \\
\text { Chinese history and Contemporary Chinese History? }\end{array}$ \\
\hline AA0203000030 & How to understand early exploration of the way for a country? \\
\hline AA0203000041 & How to understand the new way of Chinese revolution? \\
\hline AA0203000052 & $\begin{array}{l}\text { How to play a role in the new period of the reform \& opening-up and modernization } \\
\text { construction? }\end{array}$ \\
\hline
\end{tabular}

The first bit and the second bit of the question code are the course code; the 3rd-6th bits are course chapter codes; the 7 th -11 th bits are the specific question codes. The 12 th bit is the check bit. In practical teaching, the automatic questioning/answering is implemented by question codes with 7-11 bits. The students' questioning interface is shown in the Fig.6.

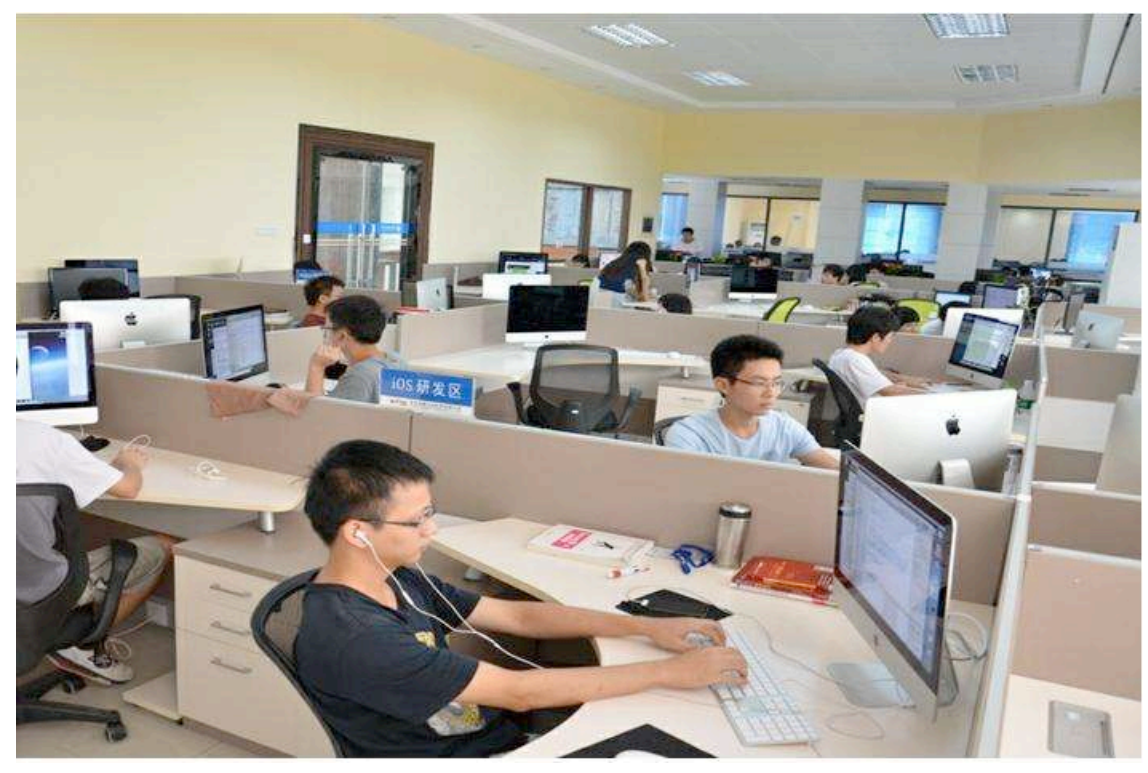

Fig. 6. Students' questioning interface 
Third, the teaching data model also contains student files, including ID, gender, age, psychological features, course progress and communication method, as shown in Table 2.

Table 2. Tab.2 Student file

\begin{tabular}{|l|l|}
\hline \multicolumn{1}{|c|}{ Item } & \multicolumn{1}{c|}{ Information } \\
\hline ID & 001 \\
\hline Gender & Male \\
\hline Age & 19 \\
\hline Psychological feature & IQ 122 temperament 75 stress 70 psychological age20 \\
\hline Course progress & $\begin{array}{l}\text { Modern History outline of China; the } 23^{\text {rd }} \text { Chapter. Comprehensive score: } 78 ; \\
\text { mean score of the latest five chapters: } 82\end{array}$ \\
\hline Communication method & 1XXXXXXXXX \\
\hline
\end{tabular}

ID is the students' username for login. Psychological features include IQ, temperament, stress, and psychological age. The numerical value is adjusted according to the students' answers to course questions. Course progress lists students' progress and scores. The student file is continuously updated in the teaching process. After the teacher completes the teaching stage, the system may offer targeted tutoring for students according to their learning situations and make the next teaching plan.

\subsection{Effect check}

Modern History Outline of China was used as the experimental course, with a total of 32 class hours. The experimental subjects were sophomores from the College of Marxism. Ninety students were extracted at random from 500 students in the college as the experimental class. An Agent-based individual network teaching system was used to teach them. Another 90 students were extracted at random as the control class, and traditional multimedia system was applied to teach them. The teachers and teaching conditions of experimental class and control class had no significant differences. The age, gender, physical qualities, and comprehension of both classes had no significant differences.

Students' learning effect was mainly judged according to the examination results. The test adopted teaching and examination as separate modes. The assessment teacher was other teacher except the course teacher. The score was unrelated to class performance, so the assessment was more objective and fair. The test results when the teaching ended are shown in Table 3.

Table 3. Test results

\begin{tabular}{|c|c|c|c|c|}
\hline Score & Control group & Experimental group & Statistical magnitude (H value) & P value \\
\hline $90-100$ & $8(8.9 \%)$ & $13(14.4 \%)$ & & \\
\cline { 1 - 3 } $80-89$ & $28(31.1 \%)$ & $37(41.1 \%)$ & & \multirow{2}{*}{40.001} \\
\cline { 1 - 3 } $60-79$ & $46(51.1 \%)$ & $36(40.0 \%)$ & & \\
\hline$<60$ & $8(8.9 \%)$ & $4(4.4 \%)$ & & \\
\hline
\end{tabular}


It is known from the table that the score of the experimental group is significantly higher than that of control group. The students whose score exceed 80 account for $55.5 \%$ in the experimental group, while the proportion is $40 \%$ for control group. The number of students failing account for $8.9 \%$ in the control group, while the proportion is lower than $5 \%$ for experimental group. Second, the investigation results of students' recognition of the two network teaching systems is shown in Table 4.

Table 4. Investigation result of students' recognition of two network teaching systems

\begin{tabular}{|c|c|c|c|c|}
\hline Recognition & Multimedia system & Individual system & Statistical magnitude (H value) & P value \\
\hline Very good & $3(3.3 \%)$ & $10(11.1 \%)$ & & \\
\cline { 1 - 3 } Good & $35(38.9 \%)$ & $70(77.8 \%)$ & & \multirow{2}{*}{40.0001} \\
\cline { 1 - 3 } Normal & $28(31.1 \%)$ & $5(5.6 \%)$ & & \\
\cline { 1 - 3 } Bad & $12(13.3 \%)$ & $1(1.1 \%)$ & & \\
\cline { 1 - 3 } Nothing & $12(13.3 \%)$ & $4(4.4 \%)$ & & \\
\hline
\end{tabular}

It is known from the table that $88.9 \%$ of students in the experimental group accepted the function of the individual network teaching system. Students' recognition of this system is significantly higher than that of the traditional multimedia system. Some students thought the individual network teaching system improved their ability to actively learn and solve problems and greatly helped them learn the Modern History Outline of China content. The advantage of this system is that students could listen to the teacher anytime and anywhere through the course unit. If a student had doubts about the teaching content in the teaching process and hoped to gain special instruction from the teacher, he could ask questions and send the questions to the teacher responsible for the course through the listening unit. Such individual teaching instruction improved the students' problem solving. After students' questions were solved, their active learning ability was cultivated. The teacher could answer questions according to the different learning situations of each student to teach students in accordance with their aptitudes. Moreover, since one teacher can be faced with several hundred of students in the teaching process, the teacher's workload can greatly decrease to significantly promote teaching effectiveness. Meanwhile, an Agent teaching model includes teaching content organization, retrieval, exchange, questioning/answering and testing. The teacher imparts the knowledge to the students. More importantly, the teacher conveys his practical experience and ideas to students so the knowledge develops in continuous accumulation. Although the application of an intelligent Agent in a distance teaching system is the research hotspot and there have been various conceptions and experimental systems at home and abroad, an Agent-based network teaching system was explored in this paper. It has strong research value and practical significance.

\section{Conclusions}

An Agent-based individual network teaching system showed significant effectiveness in the network teaching of the Modern History Outline of China course. Indi- 
viduation and intelligence of the Agent technology promoted the effectiveness of the development of network teaching. Agent technology provided technological and theoretical support for distance education. Agent-based individual network teaching system did not just achieve rational allocation of teachers and teaching resources, but it also offered better network learning experiences for students and met their individual needs. It had high practical value. Because the researcher's time and research conditions were restricted, it is necessary to further study potential problems. Future research needs to focus on learning content organization in the teaching process, including the correlation among knowledge points of courses.

\section{References}

[1] Greenhow, C., Askari, E. Learning and teaching with social network sites: A decade of research in K-12 related education. Education \& Information Technologies, 2015, vol. 22, pp. 1-23.

[2] Goić, A., Cordella, P., Aravena, L., et al. Learning about a fish from an ANT: actor network theory and science education in the postgenomic era. Cultural Studies of Science Education, 2015, vol. 10(1), pp. 83-107. https://doi.org/10.1007/s11422-013-9498-3

[3] Alvaro, M., John, P. Networked Learning and Network Science: Potential Applications to Health Professionals' Continuing Education and Development. Journal of Continuing Education in the Health Professions, 2015, vol. 35(3), pp. 211-219. https://doi.org/10.1002/ chp. 21295

[4] Feldstein, A., Gower, K. Using Social Network Analysis to Explore Digital Student Interactions and Business Competency Learning in a Web-based Educational Platform. International Journal of Information Systems \& Social Change, 2015, vol. 6(1), pp. 1-23. https://doi.org/10.4018/ijissc.2015010101

[5] Wang, C., Zhang, C., Ni, J. Social network, intra-network education spillover effect and rural-urban migrants' wages: Evidence from China. China Economic Review, 2015, vol. 35, pp. 156-168. https://doi.org/10.1016/j.chieco.2015.03.004

[6] Chow, A.S.Y., Loo, B.P.Y. Applying a World-City Network Approach to Globalizing Higher Education: Conceptualization, Data Collection and the Lists of World Cities. Higher Education Policy, 2015, vol. 28(1), pp. 107-126. https://doi.org/10.1057/hep.2014.31

[7] Isba, R., Woolf, K., Hanneman, R. Social network analysis in medical education. Medical Education, 2017, vol. 51(1), pp. 81-88. https://doi.org/10.1111/medu.13152

[8] Omar, H. Intelligent Traffic Information System Based on Integration of Internet of Things and Agent Technology. International Journal of Advanced Computer Science \& Applications, 2015, vol. 6(2), pp. 623-626. https://doi.org/10.14569/IJACSA.2015.060206

[9] Freitas, A., Schmidt, D., Panisson, A., et al. Applying Ontologies and Agent Technologies to Generate Ambient Intelligence Applications. Communications in Computer \& Information Science, 2015, vol. 498, pp. 22-33. https://doi.org/10.1007/978-3-662-46241-6 3

[10] Wang, X., Cheng, Y., Wang, W., et al. A Network Meta-analysis of the Effect of Three Kinds of Teaching Strategies in Medical Clinical Education in China. China Continuing Medical Education, 2016, vol. 8(32), pp. 19-22.

[11] Motomura, S., Kawamura, T., Nakatani, R., et al. P2P Web-based Training System Using Mobile Agent Technologies. International Journal of Network Security, 2015, vol. 18(1), pp. $42-54$. 


\section{$7 \quad$ Author}

Xianguo Jia is a lecturer in the School of Marxism, Bengbu Medical College, Bengbu 233030, China (jiaxianguo110@163.com).

Article submitted 22 October 2017. Published as resubmitted by the authors 13 January 2018. 